Journal of Patient-Centered

\title{
What Outcomes Matter to Patients After Joint or Spine Surgery?
}

Robin R. Whitebird

Leif I. Solberg

Christine K. Norton

Jeanette Y. Ziegenfuss

Stephen E. Asche

Elizabeth S. Grossman

Follow this and additional works at: https://aah.org/jpcrr

Part of the Health Services Research Commons, Musculoskeletal Diseases Commons, Orthopedics Commons, Rehabilitation and Therapy Commons, and the Surgery Commons

\section{Recommended Citation}

Whitebird RR, Solberg LI, Norton CK, Ziegenfuss JY, Asche SE, Grossman ES. What outcomes matter to patients after joint or spine surgery? J Patient Cent Res Rev. 2020;7:157-64. doi: 10.17294/

2330-0698.1738

Published quarterly by Midwest-based health system Advocate Aurora Health and indexed in PubMed Central, the Journal of Patient-Centered Research and Reviews (JPCRR) is an open access, peer-reviewed medical journal focused on disseminating scholarly works devoted to improving patient-centered care practices, health outcomes, and the patient experience. 


\section{What Outcomes Matter to Patients After Joint or Spine Surgery?}

Robin R. Whitebird, PhD, ${ }^{1}$ Leif I. Solberg, MD, ${ }^{2}$ Christine K. Norton, MA ${ }^{3}$ Jeanette Y. Ziegenfuss, PhD, ${ }^{2}$ Stephen E. Asche, MA, ${ }^{2}$ Elizabeth S. Grossman, $\mathrm{MPH}^{2}$

${ }^{1}$ School of Social Work, Morrison Family College of Health, University of St. Thomas, St. Paul, MN; ${ }^{2}$ HealthPartners Institute, Minneapolis, MN; ${ }^{3}$ patient advocate/researcher

\begin{abstract}
Purpose
Methods

Results

Patient-reported outcome measures (PROMs) are increasingly used in clinical care, but there have been few studies of what patients identify as the most important outcomes.

Semi-structured interviews were conducted with 65 patients undergoing hip or knee replacement, spinal discectomy/laminotomy, or a spinal fusion. Interviews focused on outcomes patients identified as important, perceived usefulness of standardized PROMs measures, and contextual situations important to their care. Data were analyzed using a directed content analysis approach.

Patients identified desired outcomes that were unique and important to them. Their preferred outcomes focused in the areas of freedom from pain, getting back to their normal life, and returning to an active lifestyle. Patients cared more about their individual preferred outcomes, which had more meaning for them, than a standardized PROM score. Patients also identified particular contextual situations that their care team was assumed to know about but that may not have been known.
\end{abstract}

Conclusions

Keywords

Patients identify specific preferred outcomes from these surgical procedures that are important and meaningful to them and that frame whether they see their surgery as a success. They also identified personal factors that they assume their surgeons know about, which affect their care and recovery. These findings underscore the importance of engaging patients in discussions about their preferences and contextual factors both prior to and after surgery. (J Patient Cent Res Rev. 2020;7:157-164.)
$\mathrm{P}$ atient-reported outcome measures (PROMs) are receiving increased attention as they move from assessing treatment effectiveness in clinical research to incorporation into clinical care. ${ }^{1}$ PROMs are designed to assess health outcomes such as quality of life, functional status, mental health, health symptoms, and experience of care. ${ }^{2}$ However, PROMs are not yet widely used or integrated into patient care for better assessing patient outcomes or improving care of individuals or groups. ${ }^{3,4}$ Currently, PROMs are primarily collected using standardized instruments

Correspondence: Robin R. Whitebird, PhD, University of St. Thomas School of Social Work, 2115 Summit Ave., Office SCB \#106, St. Paul, MN 55105 (rrwhitebird@stthomas.edu) producing quantitative scores based on patient function and symptoms. It is unclear whether patients perceive this type of information to be useful to their care. An increasing focus on patient-centered care has heightened interest in obtaining patient perceptions about PROMs and which outcomes patients care most about. ${ }^{5}$

Marshall et al noted, in 2006, that there is a lack of clarity about the use of PROMs in clinical care and how to facilitate their use with patients. ${ }^{6}$ Researchers investigating PROMs have identified a number of challenges to their effective use in clinical settings, including how to collect, incorporate, make sense of, and use PROM data in meaningful ways. ${ }^{3,6-8}$ A further concern is the lack of patient involvement in the creation of the measures themselves. Wiering et al found that while patient involvement in PROM development is 
essential for creating valid instruments, patients are not always involved and, when they are, their level of involvement varies significantly. ${ }^{1}$

Since the use of PROMs in clinical settings for assessing patient outcomes is currently in formative stages, ${ }^{9}$ this study investigated the potential to use PROMs as both a tool for quality reporting and a patientcentered enhancement of clinical care. The study, called PROMOTE (PROM Optimization through Technology and Engagement) is a multiphase evaluation of an initiative by a large Midwestern medical group to systematically collect and use PROMs for both reporting and clinical care in orthopedics and neurosurgery, with an initial focus on joint replacement and spinal surgery.

PROMOTE began in 2017 by interviewing patients before or after joint replacement or spinal surgery to learn their perspectives on the following questions:

1) What are the most important outcomes patients hope for from joint replacement or spinal surgery?

2) To what extent were the scores they received on current PROMs (Oswestry Disability Index, Oxford Knee Score, Oxford Hip Score) useful to them?

3) What information about their personal situation (ie, personal contextual information) should their doctors be aware of in providing them with the best patient-centered care?

\section{METHODS}

\section{Participants}

Study participants were a cross-sectional sample of all orthopedic and neurosurgery adult patients who had, or were about to have, a hip or knee replacement, a spinal discectomy/laminotomy, or a spinal fusion in $2017 / 2018$ by a surgeon in the study health system. Patients were eligible for participation if they were 18 years old or older and had scheduled or recently experienced one of the surgical procedures at 1 of 3 time points: preoperation, 3 months postoperation, and 12 months postoperation. These time points aligned with patient care and reporting requirements.

A nonprobability quota sampling strategy was used to provide equivalent representation of patients across procedures and time points. Patients were selected consecutively in the sample frame, and after the quota was met for each cell, no further recruitment was conducted for that group. Patients were identified using administrative data. There were 239 patients identified as potentially eligible; of these, 109 were contacted regarding study participation and 65 completed a telephone interview. The study participation rate was $60 \%$ of those eligible and contacted.

\section{Procedures}

Eligible participants received an introductory letter signed by the department head and principal investigator. Potential participants were recruited by telephone contact. Trained interviewers first obtained consent and then conducted interviews via telephone. Preoperative patients completed interviews an average of 16.4 days prior to surgery (range: 3-44). Postoperative patients completed 3-month interviews an average of 126 days from surgery (range: 77-169) and 12-month interviews an average of 391 days from surgery (range: 329-468). Average interview length was 11 minutes (range: 6-29 minutes); postoperative interviews were slightly longer. Participants received a \$20 gift card as a thank you for completing the interview. All interviews were audio-recorded with interviewers capturing interview notes.

Two versions of a semi-structured interview guide were used, one for preoperative and one for postoperative patients. The interviews contained 9 open-ended questions designed to be used with a set of structured probes. Questions focused on: 1) how the medical condition necessitating surgery affected their everyday life preoperatively; 2) the most important factors considered when deciding to have surgery; 3) the outcomes/results desired or hoped for; 4) the perceived usefulness of standardized scored instruments to track individual outcomes and progress; 5) the usefulness of personally identified important outcomes; 6) outcomes they viewed as important to track in their surgery; and 7) what contextual information about their life would be important for their health care team to know to better manage their recovery plan. The study was reviewed, approved, and monitored by the local institutional review board.

\section{Data Analysis}

Interview data were transcribed and prepared for analysis by the survey research center affiliated with the health plan; patient-identifying information was 
removed from study transcripts. The qualitative software NVivo (version 11.4.3 for Mac) was used for structuring and coding the data. A directed content analysis approach was used to identify patterns and themes in the data. ${ }^{10}$ The data analysis team was comprised of the authors, each of whom reviewed the data independently and then met regularly to review, discuss, and identify emerging codes, categories, and themes arising from the data. Data analysis employed an iterative process using a constant comparative method, assessing and discussing coding differences until consensus was reached on final categories and themes. ${ }^{11}$ The final coding scheme was then applied to all data. A detailed codebook and audit trail were kept to enhance the rigor of the analysis. ${ }^{12}$

\section{RESULTS}

There were 65 participants in the study -20 with knee replacement, 18 hip replacement, 18 spine discectomy/ laminectomy, and 9 spinal fusion (Table 1). Study participants were equally divided on gender, although this varied by procedure (Table 2). Patients were 36 to 86 years old (mean: 64 years), predominantly married and employed for wages or retired, and were highly educated. Participants across the 4 groups did not differ on demographic characteristics, including age (ANOVA, $\mathrm{P}=0.36$ ), gender (Fisher's exact, $\mathrm{P}=0.11$ ), marital status (Fisher's exact, $\mathrm{P}=0.64$ ), employment (Fisher's exact, $\mathrm{P}=0.59$ ), or education (Fisher's exact, $\mathrm{P}=0.51$ ).

There were 3 overarching themes in the patient interviews: patient-preferred outcomes, patient perceptions of standardized PROMs scores, and contextual information important for care planning. Subthemes were identified within each theme.

\section{Patient-Preferred Outcomes From Joint and Spine Surgery}

Patients identified specific outcomes that were important to them in surgery for joint and spine procedures. While their preferred outcomes fell into the 3 subthemes outlined in this section, patients cared most about the unique individual outcomes they identified. There were few differences among procedures in what patients identified as most important, with knee replacement patients more focused on returning to an active lifestyle than other procedures.

1) Freedom From Pain, Able to Move Again: Patients frequently identified pain as the primary reason underlying their decision to have surgery. They talked about how unrelenting their pain was: "The pain lasted so long that I felt it [surgery] was necessary" and "I just wanted to get rid of the pain. That was the main thing." Many patients expressed reservations about having the surgery but indicated that the pain became the ultimate factor in their decision to move forward with it: "I was willing to take the chance because I was in such continual excruciating pain."

While pain relief itself was the focus for many, others discussed pain in relation to specific activities like mobility and walking. Patients often focused on pain they experienced during daily movement: "To at least have motion when there was no pain when you are taking a step" and "I was in a lot of pain. It was hard walking and hard lifting my leg ... it pretty much impacted everything." They reflected on how pain impacted their ability to walk for function or leisure: "It pretty much changed my life. I couldn't do anything; or, do what I wanted to do or go where I wanted to go. It was very difficult."

Table 1. Study Population by Time and Procedure

\begin{tabular}{|c|c|c|c|c|}
\hline Procedure & $\begin{array}{c}\text { Preop } \\
\text { n (total eligible) }\end{array}$ & $\begin{array}{l}\text { 3-Month Postop } \\
\text { n (total eligible) }\end{array}$ & $\begin{array}{l}\text { 12-Month Postop } \\
\text { n (total eligible) }\end{array}$ & Total \\
\hline Hip replacement & $6(33)$ & $6(21)$ & $6(21)$ & 18 \\
\hline Knee replacement & $6(24)$ & $7(21)$ & $7(21)$ & 20 \\
\hline Spine discectomy/laminotomy & $5(26)$ & $6(21)$ & $7(21)$ & 18 \\
\hline Spine fusion & $2(9)$ & $N / A^{*}$ & $7(21)$ & 9 \\
\hline TOTAL & $19(92)$ & $19(63)$ & $27(84)$ & 65 \\
\hline
\end{tabular}

*There is no assessment conducted for spine fusion patients at 3 months postoperation. 
Table 2. Participant Demographics

\begin{tabular}{|c|c|c|c|c|c|}
\hline Characteristic & $\begin{array}{c}\text { Knee } \\
\text { Replacement } \\
n=20\end{array}$ & $\begin{array}{c}\text { Hip } \\
\text { Replacement } \\
n=18\end{array}$ & $\begin{array}{c}\text { Spine } \\
\text { Discectomy/ } \\
\text { Laminotomy } \\
n=18\end{array}$ & $\begin{array}{c}\text { Spine } \\
\text { Fusion } \\
n=9\end{array}$ & $\begin{array}{l}\text { Total } \\
\mathrm{N}=65\end{array}$ \\
\hline \multicolumn{6}{|l|}{ Gender } \\
\hline Male & $30 \%$ & $56 \%$ & $50 \%$ & $78 \%$ & $49 \%$ \\
\hline Female & $70 \%$ & $44 \%$ & $50 \%$ & $22 \%$ & $51 \%$ \\
\hline \multicolumn{6}{|l|}{ Age in years } \\
\hline Range (mean) & $51-86(65.0)$ & $45-77(65.5)$ & $36-79(59.9)$ & $56-86(65.2)$ & $36-86(63.8)$ \\
\hline \multicolumn{6}{|l|}{ Marital status } \\
\hline Married/With partner & $80 \%$ & $72 \%$ & $89 \%$ & $89 \%$ & $82 \%$ \\
\hline Divorced/Widowed/Single & $20 \%$ & $28 \%$ & $11 \%$ & $11 \%$ & $18 \%$ \\
\hline \multicolumn{6}{|l|}{ Employment } \\
\hline Employed for wages/Self-employed & $40 \%$ & $44 \%$ & $56 \%$ & $22 \%$ & $43 \%$ \\
\hline Retired or homemaker & $50 \%$ & $44 \%$ & $33 \%$ & $44 \%$ & $43 \%$ \\
\hline Not working (+ unable, disability) & $10 \%$ & $11 \%$ & $11 \%$ & $33 \%$ & $14 \%$ \\
\hline \multicolumn{6}{|l|}{ Education } \\
\hline High school/Graduated/GED & $10 \%$ & $18 \%$ & $11 \%$ & $0 \%$ & $11 \%$ \\
\hline Some college & $25 \%$ & $29 \%$ & $17 \%$ & $22 \%$ & $23 \%$ \\
\hline College graduate & $60 \%$ & $29 \%$ & $44 \%$ & $44 \%$ & $45 \%$ \\
\hline Graduate school & $5 \%$ & $24 \%$ & $28 \%$ & $33 \%$ & $20 \%$ \\
\hline
\end{tabular}

Mobility also included navigating stairs: "to be able to bend my knees and walk up and down stairs without pain." This was especially critical for people who were required to climb stairs to enter their homes or access second-floor rooms such as a bathroom.

2) To Get Back to My Life: The second subtheme addressed quality of life and ability to fulfill normal everyday functions physically and mentally, including engaging in daily routines and relationships. Patients talked of their desire for normality in their life: "I wanted to be normal again. I wanted to not have so many restrictions against my body - better quality of life" and "To get back to something normal, a normal life, and to be able to stand for an extended period of time. Even going grocery shopping and just to carry on somewhat of a normal life."

For others the primary focus was the stress their condition had on the quality of their life and the challenge to family and relationships. "My quality of life was pretty dull. I couldn't do anything with my yard work, I couldn't cook, I couldn't bake, I couldn't stand too long to do dinners; I could just do TV dinners. It was causing a lot of tension between me and my husband. No sex, no intimacy, no nothing. It's been too long for me to probably salvage what I have because I couldn't do anything. I couldn't ride a motorcycle with him. I couldn't get into a car by myself, he had to assist me. A lot of 'NOs' kind of made it rough for us."

Patients talked not only about the stress placed on their relationships but also about their ability to care and provide for their family: "To be able to take care of my family and do the things that I needed to do as a mother, wife, and business owner" and "It was affecting my sleep, my ability to do my work and take care of my family."

The desire for normality in their lives and relationships as well as the ability to engage in everyday life requirements was a prominent theme in deciding to have surgery and a primary focus of desired outcomes following surgery. 
3) Return to an Active Lifestyle: Patients also focused on returning to an active lifestyle or activities/sports they had long enjoyed. Some patients simply identified as being an active person in how they live their daily life and desired to continue that: "I'm a carpenter, so run and get a tool. Mow the lawn again. Get out and stain decks. I'm a very active person on house repair. I just wanted to be able to get out and do well with ladders and roofs again."

Others identified themselves as an active person with an active lifestyle: "I wanted to get back my active life, so, hiking, traveling, babysitting my grandchildren, and driving" and "I'm very active so that was important to me, so that I could get back to normal. I do yoga, swimming, walking, and some light weightlifting."

For others, their desired outcome focused on returning to a loved sport or activity they had enjoyed and was a normal part of their routine: "I used to bowl. I used to play golf, but I haven't played golf in a long time because of pain" and "I am a softball player and hockey player. I had to quit doing it to just cope, so I was hoping to get back to doing all that stuff."

For these patients, their identity and active lifestyle were intricately tied together, and to feel like themselves again meant engaging in life though activity and sports.

\section{Patient Perception of Standardized Scores}

Standardized PROM instruments are exemplified by the Oxford Knee Score, ${ }^{13}$ which produces a summary score ranging from 0 to 48 (each response: 0 to 4 ) to 12 questions about specific functions over the prior 4 weeks. We asked patients about their perceptions of the usefulness of such a standardized score compared to the individualized outcome that they had identified as important to them to track their recovery and outcomes following surgery. Of the 65 patients interviewed, $63 \%$ preferred an individually selected outcome, $20 \%$ preferred a standardized score, and $14 \%$ could not state a preference; $85 \%$ said they would find an individualized outcome useful, 2\% said they would not find it useful, and $14 \%$ could not choose. Of the same 65 patients, $60 \%$ of patients thought a standardized score could be useful to track their recovery, $32 \%$ said it was not useful, and $8 \%$ could not rate this.
Most patients didn't remember receiving score information following surgery (although it is reported as part of standard patient care), or they perceived the score was for the surgeon, not for them. Many also reported that they did not understand what the score meant. Patient comments about scores included "It's more useful to the doctors than it is to me I guess" and "I guess not very useful to me. I don't really know what the standard is. I wouldn't necessarily know what that number meant" and "It's not useful because everybody is different."

For those who did find standardized scores useful, they most often pointed to the accuracy of numerical scales and their ability to compare progress to others: "I would prefer to use a numerical scale. I think it's a more accurate assessment of my condition" and "Probably the score, so I could compare with others."

When asked about their perception of using an individualized outcome for tracking their recovery and outcomes following surgery, the majority of patients indicated that information specific to them and their current situation would be far more useful. One patient expressed the thinking of many when she said "That would be very useful because that pertains specifically to me instead of a group of people. It just makes more sense to deal with an individual person instead of everybody. For example, at this point, you should be at this stage or you're doing this, and this seems to be better for you. That stuff makes more sense to me than the other [standardized score]."

\section{Contextual Information Important for Care Planning}

Finally, we asked patients about contextual information the care team should know about their life situation that would be important for planning for their care and recovery. Most patients expressed a belief that their physicians and care team knew everything they needed to know about them, primarily from their medical record or their relationship with their primary care physician. "I think they had all the information they needed" or "They knew what I needed" was a common response.

When queried further, however, many patients identified concerns they had regarding care and recovery. Their concerns centered around 4 areas: 
functional concerns postsurgery; care they provide for others; physical/mental health concerns; and concerns about surgery and recovery.

\section{Functional Concerns Postsurgery: Functional} concerns focused on issues such as living alone, using stairs, handicap accessibility, transportation issues, and work concerns such as the ability to perform needed travel. Some patients expressed a host of concerns by simply saying "I live alone," assuming the implications - I have no one to help me - were clear. Transportation, getting in and out of vehicles, and handicap needs all were identified. The most frequently cited concern was how they would navigate stairs. People talked about the number of stairs they had to navigate getting in and around their homes, and for some, bathrooms were only accessible by stairs. As one patient noted, "Stairs is the major issue."

Care They Provide for Others: A related concern involved responsibilities they had for others. Parents, especially mothers, expressed concern about caring for their young children. People who had cats and dogs expressed concern about how they would care for their pets, and in one case, a primary caregiver for a disabled family member talked of his concern: "My primary concern involves the fact that I'm a full-time primary caregiver for a disabled family member who requires maximum assistance with things like transfers."

Physical and Mental Health Concerns: Contextual issues around physical and mental health concerns focused on the impact of surgery on comorbid medical conditions and anxiety and fear about surgery. Patients worried about how the surgery would (or did) impact other health conditions such as diabetes, Parkinson's disease, and post-polio syndrome symptoms. Mental health concerns focused primarily on anxiety and fear regarding pain, surgery, and recovery. As one patient noted, "I am afraid of this whole surgery I am going to do ... but I think it is just something I have to do."

Concerns About the Surgery and Recovery: Surgery concerns also went beyond fear and anxiety. Patients expressed concern and surprise that they would (or had) only met their surgeon the day of the surgery: "To be truthful, one of the biggest things was I didn't meet the surgeon that was doing the work until an hour before I got on the table." Patients talked of wanting to know the surgeon or have a relationship prior to surgery. They also expressed concern regarding anesthesia during the surgery and the use of pain medications after the surgery. "I wish I could've just picked up the phone and asked someone, 'is it OK to take my pain killers at this point in time in recovery, or, how much is a normal amount of different pain killers at this point in my recovery?' ... There were times in my recovery where I thought, 'Man, I shouldn't be needing the prescription stuff anymore."

\section{DISCUSSION}

Despite a growing interest in measuring patient-reported outcomes, few studies have explored what patients identify as important to them and their preferences for specific outcomes and recovery from these procedures. While pain relief was a primary focus, patients also identified unique aspects regarding pain relief, as well as other specific outcomes of great importance that drove their decision to have surgery. These outcomes focused on aspects of getting back to a normal life and returning to an active lifestyle, framing how patients evaluated their surgical outcomes and recovery and whether they perceived it to be successful. Patients wanted to achieve individualized outcomes that they identified, understood better, and had more meaning for them than standardized PROM scores. Finally, patients identified contextual factors in their lives that affected the progress of their recovery but that they were not often asked about. These findings underscore the value and importance of identifying the unique outcome preferences and contextual needs of each patient and addressing them both before and after surgery.

The results of our study indicate that patients define outcomes from these surgical procedures that are uniquely important to them and their interactions with their care team. This may appear to be common sense but is not well-represented in the literature. Current PROMs assess outcomes perceived by clinicians to be important to patients and are represented by scores focused on measuring aggregate symptoms and functioning. ${ }^{14-18}$ While many clinicians describe PROMs as useful, they seem to see their value more in assessing patient experience and expectations of clinical care ${ }^{19,20}$ PROMs can provide a window into patient experience, but unless they are structured based on patient perceptions of their preferred outcomes, they may not provide a clear view of patient expectations. 
This has important implications for both treatment decisions and what patients will consider to be a successful surgery. In a 2018 study of hip/knee surgery, Wiering et al found that patients' preferences and expectations for certain outcomes framed their perceptions of improvement due to surgery. ${ }^{21}$ They concluded that tailoring treatments using patient preferences and managing their expectations were of great importance. Expanding the use of PROMs to not only assess symptoms, outcomes, and patient experience, but to also engage patients in treatment decisions and track outcomes identified by them as important, are growing areas of interest in clinical settings. ${ }^{17,22}$

PROMs most often take the form of self-report on standardized measures such as Oxford Knee Score or Oxford Hip Score. We found these measures can have little meaning to patients, who did not understand how to interpret the score or how it applied to them and their recovery. Many patients did not remember receiving the score or found it confusing or thought it was for the doctor, not for them. Most of these patients expressed a desire for PROMs that were more meaningful and individually tailored to them and that they understood better. In a study of clinician and patient views of PROMs, Hildon et al found the most important aspects of PROMs for patients were language that would be more personally meaningful and scales that made more sense to them. ${ }^{23}$ Educating patients and clinicians about PROMs and how to interpret their scores is an important component of integrating such measures into clinical care. These findings suggest it is important to include discussion and assessment of individually preferred outcomes, since they are more meaningful for patients.

Engaging patients more consistently in their own care, treatment, and recovery could also address a troubling factor we identified in our study, that patients assumed their health care providers knew everything about their life needed for their recovery following surgery, either from their relationships with providers or from their medical record. Patients, however, are not often asked about important contextual factors in their life that could be important in care and recovery. When we engaged patients about this, we found they had a number of concerns about surgery and aftercare, especially pain management and how surgery could affect comorbid conditions. They also expressed concern about addressing functional needs after surgery, such as navigating stairs and transportation. They expressed concern about pets that needed to be fed and walked and about caring for family members. In interviews with postoperative patients, many talked about how their recovery took far longer and was more difficult than expected. Engaging patients more directly in their care and treatment may help clarify patient perceptions and expectations, preparing them to be an active part of their care planning and recovery.

\section{Limitations}

Limitations to the current study include that it is exploratory in nature, collecting data that are designed for guiding later, more definitive studies. However, the sample size was large and unique for a qualitative study, representing the experiences of patients preoperatively and postoperatively for 4 different procedures. The care system and patients in this study may not be representative. However, these interviews do begin to fill a surprising gap in the literature about the perceptions and expectations of patients who are often not represented in identification of PROMs. It is worth noting that one study investigator (C.K.N.) is a patient advocate with experience in health care research.

\section{CONCLUSIONS}

The development of individualized patient-reported outcome measures that support patient-centered care could have many benefits for patients and providers. ${ }^{22}$ PROMs can be used to engage patients in their care and treatment, helping to identify what they perceive as important and leading to treatment decisions more aligned with patient preferences and expectations. If PROMs include identification of what patients most want as outcomes, they could also help focus postoperative care on those outcomes. Having patients who are more engaged in their care may improve preparation and adherence to challenging aspects of recovery from surgical procedures.

Individualized PROMs also can bring important aspects of patient health, such as quality of life, mental health, satisfaction, and well-being, into care conversations about treatment options and outcomes. Bringing the patient voice and experience into the clinical 
interactions of health care through the development and use of individualized PROMs in clinical settings is an important and foundational component to moving us to a truly patient-centered care system.

\section{Patient-Friendly Recap}

- Patients receiving joint replacement or spinal surgery were asked what outcomes were most important to them.

- Patients identified individually selected outcomes (ie, those most meaningful to them) and preferred those measures to standardized measures when evaluating the success of their surgical procedures.

- The authors also learned that patients can identify factors in their lives that may affect recovery, but clinicians are often unaware of (and do not ask about) such factors.

\section{Author Contributions}

Study design: Whitebird, Solberg, Ziegenfuss, Asche. Data acquisition or analysis: all authors. Manuscript drafting: Whitebird, Solberg, Asche, Grossman. Critical revision: all authors.

\section{Conflicts of Interest}

None.

\section{Funding Sources}

Research reported in this publication was supported by the Agency for Healthcare Research and Quality under award number R18HS025618. The content is solely the responsibility of the authors and does not necessarily represent the official views of the U.S. Department of Health and Human Services.

\section{References}

1. Wiering B, de Boer D, Delnoij D. Patient involvement in the development of patient-reported outcome measures: a scoping review. Health Expect. 2017;20:11-23. CrossRef

2. Weldring T, Smith SM. Patient-reported outcomes (PROs) and patient-reported outcome measures (PROMs). Health Serv Insights. 2013;6:61-8. CrossRef

3. Black N. Patient reported outcome measures could help transform healthcare. BMJ. 2013;346:f167. CrossRef

4. McKenna SP. Measuring patient-reported outcomes: moving beyond misplaced common sense to hard science. BMC Med. 2011;9:86. CrossRef

5. Solberg LI, Asche SE, Butler J, et al. Patient-centered outcomes measurement: Does it require information from patients? $J$ Patient Cent Res Rev. 2017;4:221-9. CrossRef

6. Marshall S, Haywood K, Fitzpatrick R. Impact of patientreported outcome measures on routine practice: a structured review. J Eval Clin Pract. 2006;12:559-68. $\underline{\text { CrossRef }}$
7. Boyce MB, Browne JP. Does providing feedback on patientreported outcomes to healthcare professionals result in better outcomes for patients? A systematic review. Qual Life Res. 2013;22:2265-78. CrossRef

8. Boyce MB, Browne JP, Greenhalgh J. The experiences of professionals with using information from patient-reported outcome measures to improve the quality of healthcare: a systematic review of qualitative research. BMJ Qual Saf. 2014;23:508-18. CrossRef

9. Wu AW, Kharrazi H, Boulware LE, Snyder CF. Measure once, cut twice -- adding patient-reported outcome measures to the electronic health record for comparative effectiveness research. J Clin Epidemiol. 2013;66(8 suppl):S12-20. CrossRef

10. Hsieh HF, Shannon SE. Three approaches to qualitative content analysis. Qual Health Res. 2005;15:1277-88. CrossRef

11. Saldaña J. The Coding Manual for Qualitative Researchers, Second Edition. Thousand Oaks, CA: Sage Publications, 2012.

12. Padgett DK. Qualitative Methods in Social Work Research, Third Edition. Thousand Oaks, CA: Sage Publications, 2017.

13. Beard DJ, Harris K, Dawson J, et al. Meaningful changes for the Oxford hip and knee scores after joint replacement surgery. J Clin Epidemiol. 2015;68:73-9. CrossRef

14. Catt S, Starkings R, Shilling V, Fallowfield L. Patient-reported outcome measures of the impact of cancer on patients' everyday lives: a systematic review. J Cancer Surviv. 2017;11:211-32. CrossRef

15. Chen J, Ou L, Hollis SJ. A systematic review of the impact of routine collection of patient reported outcome measures on patients, providers and health organisations in an oncologic setting. BMC Health Serv Res. 2013;13:211. CrossRef

16. Holmes MM, Lewith G, Newell D, Field J, Bishop FL. The impact of patient-reported outcome measures in clinical practice for pain: a systematic review. Qual Life Res. 2017;26:245-57. CrossRef

17. Kotronoulas G, Kearney N, Maguire R, et al. What is the value of the routine use of patient-reported outcome measures toward improvement of patient outcomes, processes of care, and health service outcomes in cancer care? A systematic review of controlled trials. J Clin Oncol. 2014;32:1480-501. CrossRef

18. Luckett T, Butow PN, King MT. Improving patient outcomes through the routine use of patient-reported data in cancer clinics: future directions. Psychooncology. 2009;18:1129-38. CrossRef

19. Waljee J, McGlinn EP, Sears ED, Chung KC. Patient expectations and patient-reported outcomes in surgery: a systematic review. Surgery. 2014;155:799-808. CrossRef

20. Zura R, Steen RG. Patient-reported outcome measures in perspective. Orthopedics. 2018;41:10-1.

21. Wiering B, de Boer D, Delnoij D. Meeting patient expectations: patient expectations and recovery after hip or knee surgery. Musculoskelet Surg. 2018;102:231-40. CrossRef

22. Lavallee DC, Chenok KE, Love RM, et al. Incorporating patient-reported outcomes into health care to engage patients and enhance care. Health Aff (Millwood). 2016;35:575-82. CrossRef

23. Hildon Z, Neuburger J, Allwood D, van der Meulen J, Black N. Clinicians' and patients' views of metrics of change derived from patient reported outcome measures (PROMs) for comparing providers' performance of surgery. BMC Health Serv Res. 2012;12:171. CrossRef

(C) 2020 Aurora Health Care, Inc. 